\title{
The Future of Sustainable Development and Agrobiodiversity in Tanzania and Uganda
}

\author{
Marta Kozicka ${ }^{1,2}$, Dolapo Enahoro ${ }^{3}$, Jeroen C.J. Groot ${ }^{4}$, Karl M. Rich ${ }^{5}$, Elisabetta Gotor ${ }^{1}$ \\ December 16, 2021 \\ 1. The Alliance of Bioversity International and CIAT, CGIAR, Rome, Italy \\ 2. International Institute for Applied Systems Analysis, Laxenburg, Austria \\ 3. International Livestock Research Institute, CGIAR, Accra, Ghana \\ 4. Farming Systems Ecology Group, Wageningen University and Research, Wageningen, \\ the Netherlands \\ 5. Ferguson College of Agriculture, Oklahoma State University, Stillwater, OK, United \\ States
}

This document is part of a series of short papers on "The Future of X", produced as part of foresight-related research supported by the CGIAR Research Program on Policies, Institutions, and Markets, and edited by Keith Wiebe (IFPRI) and Steven Prager (Alliance of Bioversity and CIAT). These short papers are intended to provide a focused, forward-looking perspective on key issues to support discussion on food, land, and water systems transformation. We thank two anonymous reviewers for their comments on an earlier draft.

This is an accepted version presented as a pre-print. It is currently undergoing final revision, editing, and production. A final version will be made available at http://foresight.cgiar.org.

\section{What's the issue?}

Biodiversity has been recognized as an inseparable component of sustainable development [1, 2]. Agricultural biodiversity, or agrobiodiversity, is one of the central elements of biodiversity that offers opportunities for multiple benefits across socioecological systems. It is wellestablished that increasing agrobiodiversity is a vital and sustainable farm- and landscapemanagement strategy that helps control pests, diseases, and weather-related stress [3-5]. Increased agrobiodiversity has also been linked with improved human diets [6-8]. In developing country contexts, it can be an effective strategy to overcome challenges associated with population growth and climate change [9]. However, these same problems put enormous stress on agrobiodiversity itself [10], mostly through land-use intensification and agricultural landscape homogenization driven by socioeconomic pressures [11-13]. Previous analysis that used a database with wide geographic and taxonomic coverage to quantify local biodiversity responses to land use and related changes showed that agrobiodiversity is deteriorating globally at alarming rates. Losses are mostly concentrated in biodiverse but poor countries [14].

Given its importance for food and nutrition security [15] and its dependence on human management [16], enhancing agrobiodiversity must be considered as a pathway and investment priority for reaching global development goals $[17,18]$. However, few studies have evaluated the socio-economic and ecological viability of agrobiodiversity options for adaptation 
and mitigation in response to future challenges brought on by climate and socio-economic change [19]. Forward-looking systems analyses that capture the complexities of external factors, human management, and potential benefits of ecosystem changes are needed [20, 21]. Such studies would be useful for decision-making on multiple levels, including through their ability to highlight the trade-offs that exist between immediate human needs and the capacity of ecosystems to provide goods and services in the long term [22].

\section{What research has been done?}

Three recent studies tried to bridge the knowledge gap on the relation between the long-term impacts of global changes on agrobiodiversity and their role in reaching global development goals [23-25]. The studies provided initial insights into the impacts of global drivers of change on socioecological systems and assessed ex-ante strategies - those based on agrobiodiversity, in particular - that improve system resilience and generate synergies across sustainable development goals. Each of the studies used the global economic model IMPACT [26] in integrated assessments with other models to analyze different scenarios of global climate, population and income change, quantifying their impacts on food and agricultural systems to 2030 or 2050 . The global results informed further national- to landscape-scale analyses. These studies quantified consequences of affected changes for specific socioecological systems, assessing vulnerabilities of the systems, and exploring agrobiodiversity-based measures that could respond more effectively to and even bounce back better after disruptions.

In the first study, Enahoro et al. linked IMPACT to CLEANED-R, an environmental impact assessment tool that computes livestock-driven changes in land-use $[25,27]$. The results were further analyzed with an integrative modelling tool, MESH, that quantifies changes in ecosystem services supply that resulted from land-use change [27]. In the second study, Kozicka et al. extended this analysis by assessing the implications of these changes for the Sustainable Development Goals (SDGs) [24]. The authors linked various models to develop a foresight tool that can quantify the impact of future demand for animal-source foods on the provision of ecosystem services and SDGs. In both studies, the tool was applied to a case-study of Tanzania until 2030 under various land-use management strategies, focusing on agroforestry and silvopasture. In the third study, Kozicka et al. linked IMPACT to a bio-economic farm-household optimization model, FarmDESIGN, to assess the impacts of crop diversity on vulnerability and resilience of a small-scale farm-household in Uganda in 2050 in response to future climate change and a large-scale banana disease outbreak [23, 29].

\section{What has the research found?}

The relationship between income and human diets, expected global population growth, and their joint impact on biodiversity and the capacities of production systems to support the provision of ecosystem services over the long-term have been identified as amongst the biggest threats to sustainable development [30,32]. Enahoro et al. showed that higher future demand for animal source foods (ASF) in Tanzania, driven by steadily rising income, will have implications for land-use change and ecosystem services (ESS) provision locally [25]. The adoption of diversified farming practices, together with advancements in crop technology, 
showed potential to almost fully mitigate the expected negative impacts. Kozicka et al. linked these cross-scale effects to the provision of SDGs [24]. The authors demonstrated that income growth and dietary change will have positive contributions to the achievement of SDG 1 (No Poverty) and SDG 2 (Zero Hunger) in Tanzania on a macro-level. However, the land-use changes associated with these poverty and dietary goals will potentially threaten achieving numerous other SDGs and more generally attaining sustainable food systems on a landscape level. Ecosystem-based contributions will primarily decline to SDGs: SDG 3 (Health), SDG 6 (Clean Water), SDG 11 (Sustainable Cities), SDG 13 (Climate) and SDG 15 (Terrestrial Life). The authors found that higher crop productivity and a redesign of agro-ecosystems to increase on-farm tree cover could significantly limit these losses.

Climate change impacts on agricultural productivity and prices will be unequally distributed across the world, with some areas actually benefiting from adjusted climatic conditions and some crop yields changing more than others [33-35]. Moreover, it is expected that climate change will increase the frequency and severity of pest and disease outbreaks [36, 37]. Kozicka et al. considered a specific farm-household with multiple objectives, such as higher income, better nutrition and healthy soil [23]. The authors then analyzed how each of these objectives could be affected by future changes in the food systems as a result of climate change, as well as a severe banana disease outbreak. They showed that the composite effects of these shifts by 2050 on a typical smallholder farm in Uganda are complex, but overall negative. The authors demonstrated, however, that increased crop diversity could improve a farm household's capacity to adapt to these shifts and hence increase its resilience measured by the recovery of the farm's performance.

\section{What gaps deserve future work?}

To ensure the sustainable use of agrobiodiversity in the future, it is imperative for investors, policy makers, and practitioners to address trade-offs between ecological and social outcomes occurring both in the short- and the long-term in decision making [38,11]. Additional work analyzing these trade-offs and constraints on the adoption of agrobiodiversity-based interventions at different scales will be useful for designing appropriate institutional and policy investments. Much of the evidence so far is highly context-specific, with more work needed to understand the potential of agrobiodiversity under varied factors of global change (e.g., population growth, globalization, and urbanization), in different agroecological systems, and for countries at diverse levels of economic development.

Integrated models built on such analyses will be particularly important to investigate and quantify complex system interactions [39-41]. Scenario analyses that link global development pathways and regional decision-making can be useful to inform how to locally ensure human well-being and environmental sustainability under global pressures, and in turn, how local level decision-making contributes to climate change management and mitigation [42]. 


\section{Links to more information}

Enahoro, D., Kozicka, M., Pfeifer, C., Jones, S., Tran, N., Chan, C. Y., Sulser, T. B., Gotor, E., \& Rich, K. M. Integrated assessment modeling of the linkages of animal source food demand to future provisioning of ecosystem services in Tanzania. Manuscript submitted for publication. (2021)

Kozicka, M., Jones, S. K., Gotor, E., \& Enahoro, D. 2021. Cross-scale trade-off analysis for sustainable development - linking future demand for animal source foods and ecosystem services provision to the SDGs. Sustain. Sci. (in press)

Kozicka, M., Gotor, E., Ocimati, W., de Jager, T., Kikulwe, E., Groot, J.C.J., Responding to future regime shifts with agrobiodiversity: A multi-level perspective on small-scale farming in Uganda. Agric. Syst. 183, 102864. https://doi.org/10.1016/j.agsy.2020.102864 (2020)

\section{References}

1. FAO. Transforming Food and Agriculture to Achive the SDGs: 20 interconnected actions to guide decision-makers. (2018).

2. Blicharska, M. et al. Biodiversity's contributions to sustainable development. Nature Sustainability vol. 2 1083-1093 (2019).

3. Di Falco, S. \& Chavas, J.-P. On Crop Biodiversity, Risk Exposure, and Food Security in the Highlands of Ethiopia. Am. J. Agric. Econ. 91, 599-611 (2009).

4. Hajjar, R., Jarvis, D. I. \& Gemmill-Herren, B. The utility of crop genetic diversity in maintaining ecosystem services. Agric. Ecosyst. Environ. 123, 261-270 (2008).

5. Kahane, R. et al. Agrobiodiversity for food security, health and income. Agron. Sustain. Dev. 2013334 33, 671-693 (2013).

6. Oduor, F. O., Boedecker, J., Kennedy, G. \& Termote, C. Exploring agrobiodiversity for nutrition: Household on-farm agrobiodiversity is associated with improved quality of diet of young children in Vihiga, Kenya. PLoS One 14, e0219680 (2019).

7. Ekesa, B., Ariong, R. M., Kennedy, G., Baganizi, M. \& Dolan, I. Relationships between land tenure insecurity, agrobiodiversity, and dietary diversity of women of reproductive age: Evidence from Acholi and Teso subregions of Uganda. Matern. Child Nutr. 16, e12965 (2020).

8. Vogliano, C. et al. Dietary agrobiodiversity for improved nutrition and health outcomes within a transitioning indigenous Solomon Island food system. Food Secur. 13, 819-847 (2021).

9. Fatima, A. et al. Loss of agro-biodiversity and productivity due to climate change in continent Asia: A review. in Plant Ecophysiology and Adaptation under Climate Change: Mechanisms and Perspectives I: General Consequences and Plant Responses 51-71 (Springer Singapore, 2020). doi:10.1007/978-981-15-2156-0_2. 
10. FAO. The State of the World's Biodiversity for Food and Agriculture. (FAO Commission on Genetic Resources for Food and Agriculture Assessments, 2019).

11. Foley, J. A. et al. Global consequences of land use. Science vol. 309 570-574 (2005).

12. Flynn, D. F. B. et al. Loss of functional diversity under land use intensification across multiple taxa. Ecol. Lett. 12, 22-33 (2009).

13. Bellard, C., Bertelsmeier, C., Leadley, P., Thuiller, W. \& Courchamp, F. Impacts of climate change on the future of biodiversity. Ecology Letters vol. 15 365-377 (2012).

14. Newbold, T. et al. Global effects of land use on local terrestrial biodiversity. Nature 520, 45-50 (2015).

15. Thrupp, L. A. Linking Biodiversity and Agriculture: Challenges and Opportunities for Sustainable Food Security. https://www.povertyandconservation.info/en/biblio/b0896 (1997).

16. Zimmerer, K. S. \& De Haan, S. Agrobiodiversity and a sustainable food future. Nature Plants vol. 3 1-3 (2017).

17. Zeng, Y. et al. Environmental destruction not avoided with the Sustainable Development Goals. Nat. Sustain. 3, 795-798 (2020).

18. Shih, W. Y., Mabon, L. \& Puppim de Oliveira, J. A. Assessing governance challenges of local biodiversity and ecosystem services: Barriers identified by the expert community. Land use policy 91, 104291 (2020).

19. Descheemaeker, K. et al. Climate change adaptation and mitigation in smallholder croplivestock systems in sub-Saharan Africa: a call for integrated impact assessments. Reg. Environ. Chang. 16, 2331-2343 (2016).

20. Mehring, M., Bernard, B., Hummel, D., Liehr, S. \& Lux, A. Halting biodiversity loss: how social-ecological biodiversity research makes a difference. Int. J. Biodivers. Sci. Ecosyst. Serv. Manag. 13, 172-180 (2017).

21. Fears, R., ter Meulen, V. \& von Braun, J. Global food and nutrition security needs more and new science. Science Advances vol. 5 eaba2946 (2019).

22. Johns, T. \& Sthapit, B. R. Biocultural Diversity in the Sustainability of Developing-Country Food Systems. Food Nutr. Bull. 25, 143-155 (2004).

23. Kozicka, M. et al. Responding to future regime shifts with agrobiodiversity: A multi-level perspective on small-scale farming in Uganda. Agric. Syst. 183, 102864 (2020).

24. Kozicka, M., Jones, S. K., Gotor, E. \& Enahoro, D. Cross-scale trade-off analysis for sustainable development - linking future demand for animal source foods and ecosystem services provision to the SDGs. Sustain. Sci. (in press).

25. Enahoro, D. et al. Integrated assessment modeling of the linkages of animal source food demand to future provisioning of ecosystem services in Tanzania. Manuscript submitted for publication. (2021)

26. Robinson, S. et al. The International Model for Policy Analysis of Agricultural Commodities and Trade (IMPACT) Model Description for Version 3. IFPRI Discuss. Pap. (2015) doi:10.13140/RG.2.1.4865.1607.

27. Pfeifer, C., Morris, J. \& Lannerstad, M. 2016. The CLEANED R simulation tool to assess the environmental impacts of livestock production. (2016).

28. Johnson, J. A. et al. Mapping Ecosystem Services to Human Well-being: a toolkit to support integrated landscape management for the SDGs. Ecol. Appl. 29, (2019). 
29. Groot, J. C. J., Oomen, G. J. M. \& Rossing, W. A. H. Multi-objective optimization and design of farming systems. Agric. Syst. 110, 63-77 (2012).

30. Springmann, M., Godfray, H. C. J., Rayner, M. \& Scarborough, P. Analysis and valuation of the health and climate change cobenefits of dietary change. Proc. Natl. Acad. Sci. 113, 4146-4151 (2016).

31. Leclère, D. et al. Bending the curve of terrestrial biodiversity needs an integrated strategy. Nature 585, 551-556 (2020).

32. Willett, W. et al. Food in the Anthropocene: the EAT-Lancet Commission on healthy diets from sustainable food systems. Lancet 393, (2019).

33. Ericksen, P., Thornton, P. \& Notenbaert, A. Mapping hotspots of climate change and food insecurity in the global tropics. CCAFS Report www.ccafs.cgiar.org (2011).

34. Knox, J., Hess, T., Daccache, A. \& Wheeler, T. Climate change impacts on crop productivity in Africa and South Asia. Environ. Res. Lett. 7, 034032 (2012).

35. Roudier, P., Sultan, B., Quirion, P. \& Berg, A. The impact of future climate change on West African crop yields: What does the recent literature say? Glob. Environ. Chang. 21, 1073-1083 (2011).

36. Donatelli, M. et al. Modelling the impacts of pests and diseases on agricultural systems. Agric. Syst. 155, 213-224 (2017).

37. Rosenzweig, C., Iglesius, A., Yang, X. B., Epstein, P. R. \& Chivian, E. Climate change and extreme weather events - Implications for food production, plant diseases, and pests. Glob. Chang. Hum. Heal. 2, 90-104 (2001).

38. Baral, H., Keenan, R. J., Sharma, S. K., Stork, N. E. \& Kasel, S. Economic evaluation of ecosystem goods and services under different landscape management scenarios. Land use policy 39, 54-64 (2014).

39. Müller, B. et al. Modelling food security: Bridging the gap between the micro and the macro scale. Glob. Environ. Chang. 63, 102085 (2020).

40. Rich, K. M. et al. Systems Approaches to Animal Disease Surveillance and Resource Allocation: Methodological Frameworks for Behavioral Analysis. PLoS One 8, e82019 (2013).

41. Grace, D. et al. Poor livestock keepers: ecosystem-poverty-health interactions. Philos. Trans. R. Soc. B Biol. Sci. 372, 20160166 (2017).

42. Bohensky, E. et al. Future makers or future takers? A scenario analysis of climate change and the Great Barrier Reef. Glob. Environ. Chang. 21, 876-893 (2011).

43. FAO. Food outlook - Biannual report on global food markets. Food Outlook - Biannual Report on Global Food Markets (FAO, 2020). doi:10.4060/CA9509EN. 